\title{
Matters for debate
}

\section{Masterclasses, excitement, enrichment, extension - what are we trying to achieve?}

\section{JOHN HERSEE}

I have been watching-and enjoying-the 1997/8 Royal Institution Christmas lectures. I was impressed by the range of topics the lecturer, Ian Stewart, managed to present and by his friendly style. The sense of enjoyment of the young people in the audience was clear.

However, at the end of the series I was left with a number of questions, which can be summarised by asking: What exactly should those who have the privilege of working with bright youngsters be trying to achieve? The question is in no way restricted to Ian Stewart's series of lectures, but applies equally to other activities-such as Saturday morning Masterclasses for those in Years 7-9.

I assume that the underlying aim of the RI lectures (and of the Masterclasses) is to stimulate young children's excitement and interest in mathematics, and to encourage them to pursue their interest and curiosity in mathematics throughout their school career and beyond. The question then arises as to whether this is best achieved by talking relatively superficially about mathematics, or by getting children to work directly with appropriate topics, while choosing those topics so that they can be extended to provide a glimpse of the larger tapestry of current research.

The point I wish to make may be illustrated by Fermat's Last Theorem. Here the proposition may be easily presented to pupils in Year 8 (even if their experience of algebra is limited). One can also indicate why a proof is needed. But the ultimate proof would appear to be completely inaccessible. Does this affect the suitability of the topic?

In the RI lectures, there were a number of points where we were told that mathematics 'could' be used to solve a problem, or to predict a result; but we never really saw how mathematics might be so used, or what it meant to say that mathematics can be so used. I have seen something similar in some Masterclasses and wonder what effect this has on pupils. The fact is that we learn what makes mathematics tick, and what is special about it, by doing mathematics: ours is not a 'spectator sport'! (Feedback from Masterclasses makes clear that the children prefer to work at tasks rather than to listen to long lectures.) It may be surprising, or intriguing, to be told that mathematics can be used to predict the weather, but the healthy mind wants to know what mathematics is used, and how it is used.

No doubt some youngsters will try to follow up a lecture. Some may happily take a long term view and accept that it will be many years before they can hope to fill in the missing details. But what about the others? Is it not possible that for them the result may be to encourage a superficial view of mathematics, to make them satisfied with talking about the discipline rather than learning by doing; might it not even, in the long term, deflect 
their interest rather than turn it on?

Perhaps I should declare my own recipe for a Masterclass for pupils in Year 8. The presentation should start from the mathematics that the class (or a majority of the class) knows. Thus, for example, it should not presume a fluency in algebra, or in algebraic manipulation, that few in the class possess. The presentation should then build on that knowledge, and extend it, so that something new is presented and learned. Some results should be properly proved (rather than merely illustrated in a few cases). At the end, students should leave with work to follow up after the class, and with material to take to school, so that teachers can see what was done, can discuss it with their pupils - and maybe even adapt it for their own subsequent use. Ideally, references to (easily available) books, in which the topic can be followed up, should be given.

A similar framework can be used for lectures to A level students though here the question of what mathematics one can assume is complicated by differences resulting from the range of backgrounds, the gap between those in Year 12 and Year 13, what kind of mathematics they are studying, and how much.

To some, my recipe may seem too obvious to be worth stating. If so, I can only say that, while I have seen many excellent Masterclasses and lectures, others have ignored one or more of my suggestions.

I hope these comments can be seen as constructive, even though they raise certain questions. The reaction of the children shows that the Masterclasses are appreciated. However, I would be interested to know whether others share my concern about the possible effects of children being given too many superficial glimpses of parts of mathematics that lie far beyond them.

JOHN HERSEE 76 Pembroke Rd, Bristol BS8 3EG 